\title{
The relationship among performance risk, safety risk, social risk, psychological risk, satisfaction and intentions to use grab service in Vietnam amid Covid-19 crisis
}

\author{
Van Dat Tran ${ }^{a^{*}}$ \\ C H R O N I C L E \\ Article history: \\ Received: July 102020 \\ Received in revised format: July \\ 242020 \\ Accepted: August 122020 \\ Available online: \\ August 122020 \\ Keywords: \\ Performance Risk \\ Safety Risk \\ Social Risk \\ Psychological Risk \\ Intentions to Use
}

${ }^{a}$ Faculty of Business Administration, Banking University, Hochiminh, Vietnam

\section{A B S T R A C T}

\begin{abstract}
This study aims to investigate the relationship among performance risk, safety risk, social risk, psychological risk, satisfaction, and intention to use Grab in Vietnam. Validated measurements were identified from a literature review. A convenience sample of 276 respondents was collected through online and offline survey. It was then analyzed by using SPSS and AMOS software. A reliability test, EFA, CFA and SEM were implemented. The results of this study indicate a negative relationship between safety risk and satisfaction and intention to use Grab cars. In addition, passengers' satisfaction influenced intentions to use Grab cars. However, performance risk and social risk show no effect on satisfaction and intentions to use Grab service. The main contribution of this study is to create a framework of the effect of perceived risk types on intention to use Grab cars. The users care about their own safety and information security. In addition, the issue of said psychological risk is important because consumers are concerned about health and infectious diseases.
\end{abstract}

(C) 2020 by the authors; licensee Growing Science, Canada.

\section{Introduction}

The explosion of the 4.0 revolution has drastically changed the way and reshaped the market in many different businesses, including the transportation sector. The taxi app, a breakthrough resulting from the 4.0 revolution with undeniable benefits that have changed the face of the transport business. The presence of mobile application technology on Android, Windows, or IOS-based working frameworks in smartphones has brought noteworthy changes in all zones, counting transport. The convenience to arrange products, aircraft tickets, trains, ships, and other modes of transportation as it were from gadgets claimed, that's commercial movement through online stage called e-commerce, has been increasingly popular with many different types of people. According to Google, 2018 was an innovation year for the ride-hailing service in Southeast Asia, with a total market value of US \$7.7 billion, up 39 percent from 2015. Transportation industry is the biggest zone of the worldwide financial system and it changes rapidly consistent with the innovations of technology. The invention of e-hailing came to be part of the taxi industry and works very well in Vietnam. Grab and the others are popular transportation modes conceptualized and developed abroad and subsequently introduced to Vietnamese transporters. However, Covid-19 crisis has dramatically ceased the unprecedented growth of taxi apps in Vietnam, especially Grab since travelers changed their intention towards taxi usages for their travel demands. Initially, trip sharing is not an attractive option anymore since travelers consider about their social distancing. At this

* Corresponding author.

E-mail address: dattv@buh.edu.vn (V. D. Tran) 
stage, travelers will lean on positively their safety rather than financial reaction. Additionally, Vietnamese Government's lockdown policies lead to ride-hailing services collapse. People are allowed to travel for essential needs exclusively. These actions are resulting from people's safety intention aiming at preventing the Covid-19 spread out opportunities. Grab's amended policies to adapt online food and grocery deliveries increasing demands, furthermore, have raised a new concern about food safety to clients since more people get involved in those food items as well as standard of delivery process. As a result, consumer intention and satisfaction towards taxi apps have been altered negatively amid Covid19 crisis. There is, however, no theoretical research about this topic in Vietnam so far. Therefore, it is a great opportunity and right time to identify the relationship between perceived risks, satisfaction and intention to use Grab cars.

Watchareebhorn Sakunlertvattana (2016) pointed out some factors influencing consumer brand choice in Bangkok. the research focuses on the result of the factors that influence people to make decision on brand choice. However, there are very few articles on Grab. In the world, there are many researches on Uber with issues such as influence factors, intention to use as well as other related topics. Wan et al. (2016) found that perceived utility affected perceived user friendliness of the Uber service. About sharing economy, Choi and Park (2014) analyzed regional factors that influence car sharing frequency such as tax revenue, commercial center, station, and bus spheres. Kim, Lee and Choi (2014) analyzed preference of car sharing with the aid of age. In addition, Pavlou and Gefen (2004) showed that perceived risk increases negative expectations and recognized psychological risk effect to driver trust (Liang, $\mathrm{Li}$ and $\mathrm{Xu}, 2018$ ). Younger era has better aim to apply than elder generation Liang

The purpose of this research is to investigate the peformance risk, social risk, safety risk, psychological risk on satisfaction and intention to use Grab's services. This paper is divided into five additional sections. Initially, the theoretical background and a review of previous studies are discussed. Second section presents the data and methodology. The empirical results are summarized in the third. Next, a discussion of results is presented. The research limitations and the conclusion are outlined in the final section.

\section{Theoretical background and hypotheses}

\subsection{Sharing economy}

According to Botsman (2010) the sharing economy refers to the technology-enabled and transient sharing or renting of personal commodities that includes a charge or other styles of financial compensation. It is regulated via a fixed of social relations such as friendships and relationships, whilst business economy is governed by the good judgment of market like price mechanism (Lessig, 2008). Shaheen, Chan and Gaynor (2016) showed that sharing economic system is a famous consumer concept that makes a speciality of access to items and services by means of borrowing and renting as opposed to owning them. Moreover, Aloni, E. (2016) stated that it is a monetary activity in which web structures facilitate peer-to-peer exchanges of diverse kinds of goods and services. Sharing economy business is often related to sustainability that determines the capacity of capital to meet current needs without undermining future generations' ability to meet their needs (Hawapi et al., 2017). Through sharing the economy, all can make complete use of their wealth through minimizing ownership expenses with the aid of renting, swapping, leasing, lending, subscribing and/or donating.

\subsection{Perceived Risk}

Around the world, there are many articles about car sharing service especially for Uber brand. Mohamad et at (2016) conducted that customer's intention to use uber service in travelling. This conceptual inquire about investigates the variables that impact the deliberate of clients to select Uber app in tourism goal over conventional taxi. Moreover, Lee et al. (2018) give an explanation about why people participate in the sharing economy: an empirical investigation of Uber. The aim of this paper is to invatigate the effects of inhibiting, encouraging, and technical influences on the intention of users to take part in the sharing economy. It found that perceived risks and perceived product quality were important predictors of the intention of users to join Uber. Individuals people with high perceived security risk were not likely to 
believe the sharing arrange and the offline benefit supplier. Liang et al. (2018) found that safety risk plays an imperative part whereas utilizing DiDi, particularly after a few dangerous occasions, clients pay more consideration to their security. Cost savings and social value had little impact on the decision to use car sharing service. Zhang et al. (2012) showed that perceived delivery risk and perceived aftersale risk significantly affect the purchasing behaviour of online consumers.

Hawapi (2017) showed the relationships between performance risk, social risk, credibility and mouthof-mouth electronics against collaborative customer intention. Sakunlertvattana (2016) conducted a research to show the relationship between influential factor and consumer brand choice. The research focuses on the effects of the factors influencing people in making brand choice decisions. The studies mentioned above are all about sharing economy and percieved risk of Uber. However, no author has yet researched Grab. This brand is one of the most popular car brand in Southeast Asia and its users also face percieved risk. It is important that we understand how our perceived risks affect our decision to use Grab's services.

\subsection{Safety risk}

Safety risk plays an imperative part whereas utilizing DiDi, particularly after a few dangerous occasions, clients pay more consideration to their security, in this way expanding theory and driver control is anticipated to diminish the seen security hazard for clients. On the contrary, some results show that there is no significant relationship between financial risk and either online or offline trust, which means that financial risk is not the main cause of reducing confidence. Besides, Joo (2017) did a research about motives for participating in sharing economy: intentions to use car sharing services. This research analyzes the reasons for involvement in sharing economy using samples from a South Korean car sharing company. Safety is another major risk issue commonly discussed in the sharing economy The safety risk is embedded in the "international economy". It stems mainly from the lack of confidence between the two sides of the information asymmetry-caused interest exchange (Gao \& Chen, 2019). Safety inspection is the most crucial factor that could attract clients to choose Grab service. Laws and guidelines are all in place to ensure Uber's customers' safety. When buyers are stressed approximately specialized issues or a total disappointment on the way to the goal, the car must encounter (Liang et al., 2018).

\section{$H_{2 a}$ : The perceived safety risk has a negative effect on the passengers'satisfaction of Grab service. \\ $H_{2 b}$ : The perceived safety risk has a negative effect on the intension to use of Grab service.}

\subsection{Social risk}

Hawapi et al. (2017) showed that social risk is the external psychological risk factor that has been identified as the probability of purchasing, contributing to other consumers' thinking less favorable. Social risk is also characterized as the possible loss of status in a social group following the adoption of a product. Social risk often occurs as the result of social humiliation and loss of social confidence when the user's friends or family equate the image of the brand with the picture they have on them, as well as internal psychological frustration in making a purchase that does not correlate to their image. According to Schaefers et al. (2015), social threat refers to the quantity to which purchase selections are believed to be judged by others and might influence one's social standing. Therefore, a higher social risk indicates confusion as to how peers will judge the consumer as a result of a purchase decision.

Hзa: The social risk has a negative effect on passengers'satisfaction of Grab service.

$H_{3 b}$ : The social risk has a negative effect on intention to use Grab.

\subsection{Performance risk}

Hawapi et al. (2017) indicated that consumers are worried about their privacy in collective use, because they use products exchanged by others. Nonetheless, other voices suggest that product ownership output risk would result in consumers moving from the traditional economic model to access dependent consumption. In the other side, Khedmatgozar and Shahnazi, (2017) showed that services cannot satisfy the 
claimed advantages or facilities. Moreover, performance risk is much like functional danger, which incorporates the idea of the consumer that a purchased product or service will no longer offer a consumer with desired benefits. Park and Tussyadiah (2017) show that performance risk is an important measurement of perceived risk. Participants of the sharing economic system also want to bear in mind overall performance risks (Chang and Wang, 2018).

$H_{1 a}$ : The perceived performance risk has a negative effect on the passengers' satisfaction of Grab service.

$H_{l b:}$ The perceived performance risk has a negative effect on the intention to use Grab service.

\subsection{Psychological risk}

According to Jacoby and Kaplan (1972) psychological risk is individuals suffer mental stress. Liang et al. (2018) found that safety risk plays an imperative part whereas utilizing DiDi, particularly after a few dangerous occasions, clients pay more consideration to their security, in this way expanding theory and driver control is anticipated to diminish the seen security hazard for clients. An observational thinking about differentiated the importance of investment funds for comfort and time as determinants of purposeful use of a car sharing value on a continuous basis. Bartel et al. (2019) show that rideshare drivers face pressures from passengers. Besides, Liang et al. (2018) found that safety risk and psychological risk are related to driver trust, significantly. Hence, we propose:

$H_{4 a}$ : The psychological risk has a negative effect on passengers'satisfaction of Grab service.

$H_{4 b}$ : The psychological risk has a negative effect on passengers'satisfaction of Grab service.

\section{Methodology}

\subsection{Research Framework}

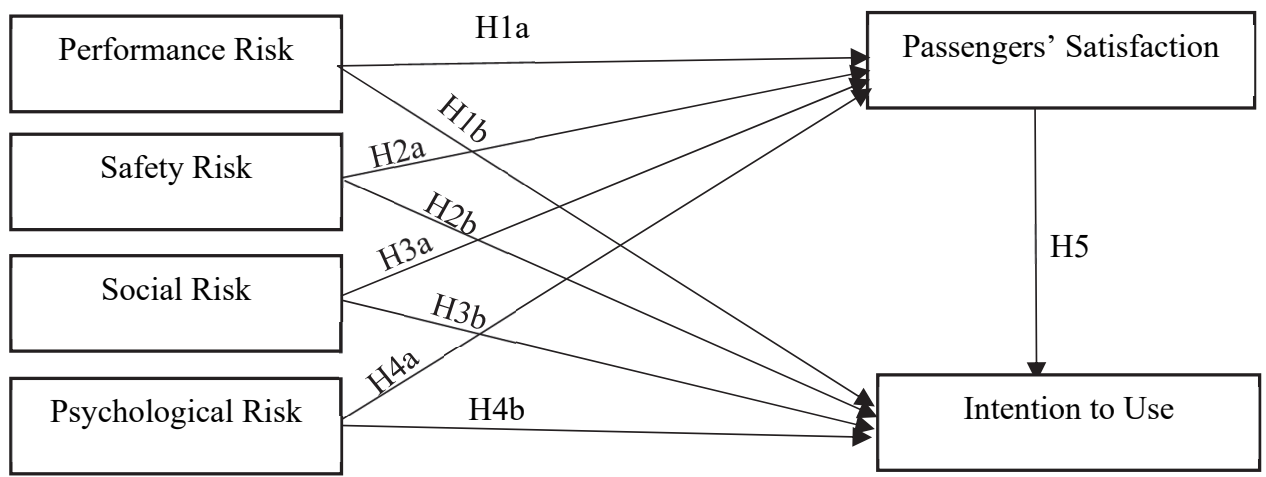

Fig. 1. Research framework

\subsection{Sample and Data collection}

The survey for the safety risk represented the first 4 items of the survey based on the Wan et al. (2016). To measure performance risks, we modified 4 items from Hawapi et al., (2017). To measure social, we included a version of scale that consisted of the 4 social items form Hawapi et al., (2017) and 3 psychological items from Malazizi et al. (2018). Finally, to measure intention to use, we adopted 3 items from Hawapi et al. (2017)

\subsection{Demographic Statistics}

The questionnaires were distributed among 300 respondents. Among which, there have been 276 responses were valid. Thus, the valid response rate of this survey is $92 \%$. There have been 24 invalid responses because the respondents have not correctly answered the reversed scale questions or left the answers blank. 


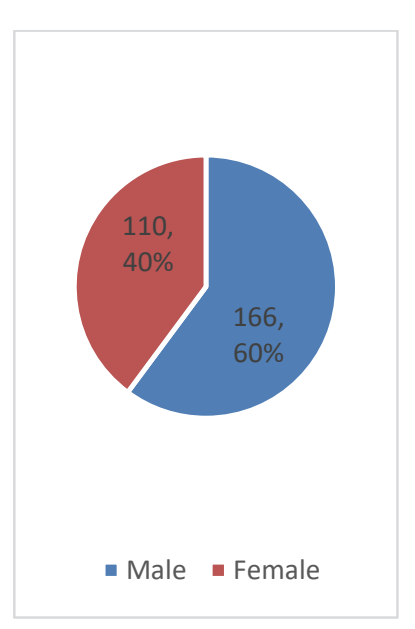

Gender

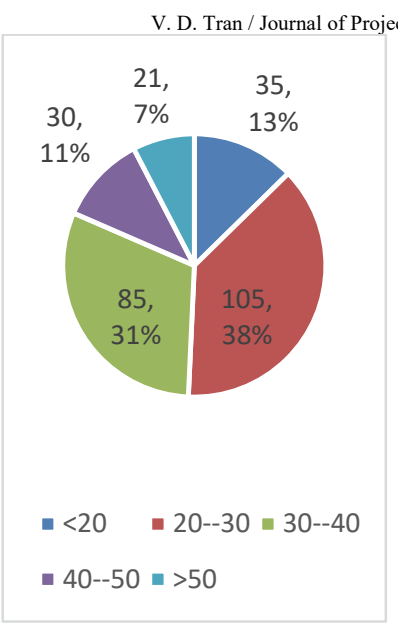

Age

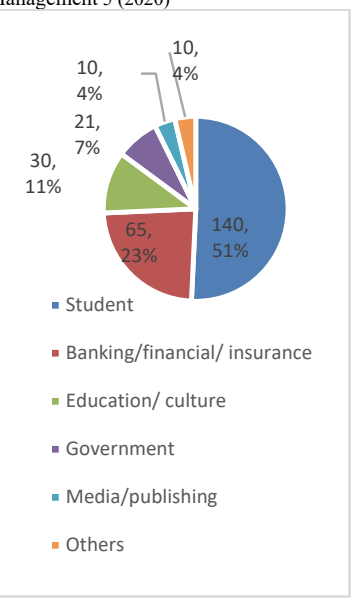

Occupation

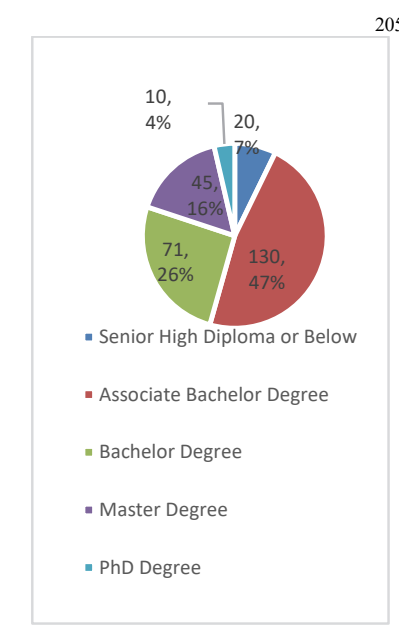

Education

Fig. 2. Personal characteristics of the participants

\section{Results and Discussion}

\subsection{Testing Measurement Model with CFA}

According to Bagozzi and Foxall (1996), NFI, IFI, and CFI are greater than 0.90, GFI and AGFI index exceeds 0.8. Chi- square/df is equal or lower 2 (Chi-Square/df $\leq 3$ can be accepted in some cases), and RMSEA is equal or lower 0.08 (RMSEA $\leq 0.05$ is excellent) (Hair et al., 1998). Those estimates are the precedents for the reliability of all factors for the next analyzing steps in this research. Comparing the current fit indices to the threshold level, the fit indices of CMIN, AGFI, and RMSEA are great. The CMIN/DF, AGFI and RMSEA satisfy the fit indices criteria perfectly. Therefore, the model fits of Confirmatory Factor Analysis is good overall. These evidence which are GFI $=0.911$, TLI $=0.967, \mathrm{CFI}=$ $0.972(>0.9)$, Chi-square $/ \mathrm{df}=1.601(<2), \mathrm{RMSEA}=0.47(<0.08)$ prove the validity and reliability of measurements. Therefore, no item of factors in this model needs to be deleted.

Table 1

Analysis of measurement model

\begin{tabular}{|c|c|c|c|c|}
\hline Factors & Std Loading & $\alpha$ & $C R$ & $A V E$ \\
\hline Performance Risk & & 0.893 & 0.893 & 0.678 \\
\hline Perf1 & 0.908 & & & \\
\hline Perf2 & 0.836 & & & \\
\hline Perf3 & 0.788 & & & \\
\hline Perf4 & 0.754 & & & \\
\hline Safety Risk & & 0.853 & 0.854 & 0.594 \\
\hline Saf1 & 0.781 & & & \\
\hline Saf2 & 0.790 & & & \\
\hline Saf3 & 0.780 & & & \\
\hline Saf4 & 0.732 & & & \\
\hline Social Risk & & 0.841 & 0.857 & 0.60 \\
\hline Soc1 & 0.751 & & & \\
\hline Soc2 & 0.826 & & & \\
\hline Soc3 & 0.867 & & & \\
\hline Soc4 & 0.644 & & & \\
\hline Psychology Risk & & 0.887 & 0.846 & 0.648 \\
\hline Psy1 & 0.770 & & & \\
\hline Psy2 & 0.760 & & & \\
\hline Psy3 & 0.881 & & & \\
\hline Passenger Satisfaction & & 0.832 & 0.904 & 0.703 \\
\hline Sat1 & 0.897 & & & \\
\hline Sat2 & 0.769 & & & \\
\hline Sat3 & 0.816 & & & \\
\hline Sat4 & 0.867 & & & \\
\hline Intention to use & & 0.832 & 0.861 & 0.675 \\
\hline 20. Int1 & 0.872 & & & \\
\hline 21. Int2 & 0.767 & & & \\
\hline 22. Int3 & 0.823 & & & \\
\hline
\end{tabular}




\subsection{Validity}

Fornell and Larcker (1981) also explain for the case if AVE is less than 0.5 and CR value higher than 0.6 , convergent validity could still be accepted. From results in Table 1, all AVE values of the seven factors are higher than 0.5; hence, convergent validity is assured. Gaski and Nevin (1985) proposed that the AVE was greater than the squared inter-construct correlation between any pair of constructs, which supports the discriminant validity of the constructs. The results have confirmed the discriminant validity of the five remaining constructs since all correlations satisfy the testing criteria. In other words, the five constructs have statistical evidence proving that they are distinct from each other. Thus, the measurement model demonstrated discriminate validity (see Table 2).

Table 2

Discriminant validity and correlations among the constructs

\begin{tabular}{lllcccc}
\hline & Performance risk & Safety risk & Social risk & $\begin{array}{l}\text { Psychotically } \\
\text { risk }\end{array}$ & Passengers' Satisfaction & Intention to use \\
\hline Performance risk & 0.687 & & & & & \\
Safe risk & 0.638 & 0.594 & & & & \\
Social risk & 0.684 & 0.685 & 0.60 & & & \\
Psychological risk & 0.650 & 0.632 & 0.681 & 0.648 & & 0.675 \\
Passengers' Satisfaction & 0.572 & 0.599 & 0.632 & 0.497 & 0.703 & \\
Intention to use & 0.622 & 0.639 & 0.602 & 0.602 & 0.594 & \\
\hline
\end{tabular}

\subsection{Model Test}

The model is tested in SEM with the same recommended value used in CFA. The results show the model fit testing. It has been found in this research that the hypotheses shown in the structural model given in Fig. 2. Model fit is acceptable $(\mathrm{CMIN}=342.2341 ; \mathrm{df}=192 ; \mathrm{p}<0.001$; $\mathrm{x}^{2} / \mathrm{df}=1.782 ; \mathrm{GFI}=0.91 ; \mathrm{CFI}=0.96 ; \mathrm{RMSEA}=0.053$ ). (see Fig. 3 ).

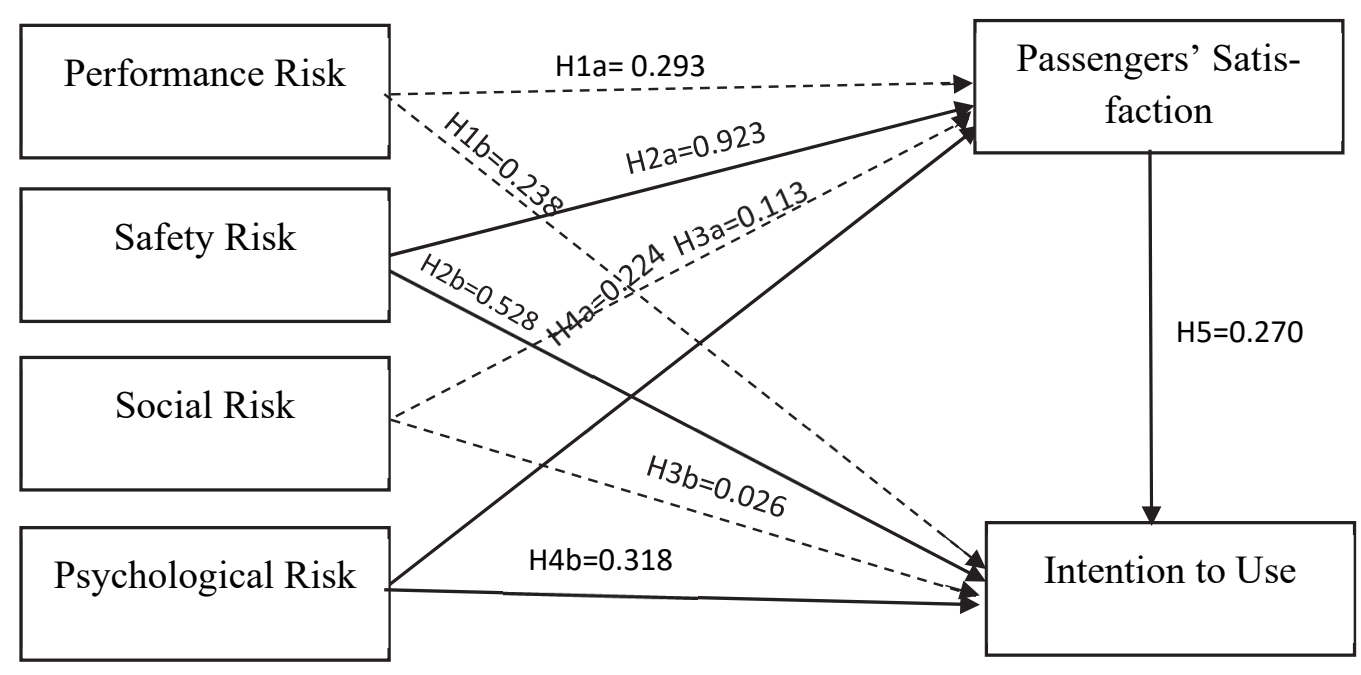

Fig. 2. Model Tests

The first hypothesis was going to test if there is any correlation between performance risk and satisfaction. The study results showed that the effect of performance risk on satisfaction and intentions to use $(\beta=0.293, \beta=0.238)$ the effect of social risk on satisfaction and intention to use $(\beta=0.113, \beta=0.026)$ are not significant. Thus, $\mathrm{H}_{1 \mathrm{a}}, \mathrm{H}_{1 \mathrm{~b}}, \mathrm{H}_{3 \mathrm{a}}, \mathrm{H}_{3 \mathrm{~b}}$ are not supported $(\mathrm{p}>0.05)$. However, the study results confirmed that safety risk negative influences on satisfaction $(\beta=0.923)$ and intentions to use Grab ( $\beta=0.528)$. Thus, $\mathrm{H}_{2 \mathrm{a}}$ and $\mathrm{H}_{2 \mathrm{~b}}$ are supported. In addition, psychological risk negative effect to customer satisfaction $(\beta=0.224)$ and intentions to use $\mathrm{Grab}(\beta=0.318)$. Thus, $\mathrm{H}_{4 \mathrm{a}}$ and $\mathrm{H}_{4 \mathrm{~b}}$ are supported. The next investigation in this study was assessing the relationship between satisfaction and intentions to use Grab. The results explored that there is a positive relation these two variables $(\beta=0.270)$. Thus, $\mathrm{H}_{5}$ is supported (see Table 3). 
Table 3

Results of the hypothesis test

\begin{tabular}{ll}
\hline Hypothesis Test & Hypothesis \\
\hline H1a: The perceived performance risk has a negative effect on the passengers' satisfaction of Grab service & Not Supported \\
H1b: The perceived performance risk has a negative effect on the intention to use Grab service . & Not Supported \\
H2a: The perceived safety risk has a negative effect on the passengers'satisfaction of Grab service. & Supported \\
H2b: The perceived safety risk has a negative effect on the intension to use of Grab service. & Supported \\
H3a: The social risk has a negative effect on passengers'satisfaction of Grab service. & Not Supported \\
H3b: The social risk has a negative effect on intention to use Grab. & Not Supported \\
H4a: The psychological risk has a negative effect on passengers'satisfaction of Grab service. & Supported \\
H4b: The psychological risk has a negative effect on passengers'satisfaction of Grab service. & Supported \\
H5: The passengers'satisfaction has a positive effect on intetion to use Grab service. & Supported \\
\hline
\end{tabular}

\subsection{Discussion}

At first, the study findings have identified that perceived risks including performance risk, safety risk, psychological risk and social risk played an integral part in consumer satisfaction and intention to use Grab. The results, however, distinct different roles of each perceived risks in customer intention and satisfaction. Particularly, safety risk and psychological risk significantly negatively effect on passengers' satisfaction and intention to use Grab more than performance and social risks. As discussed in the literature review, Mohamad et al. (2016) found that perceived usefulness influenced perceived ease of use of the Uber service. This paper proposes, additionally, that perceived safety influence the intention of customers to use Grab service compared to offline taxi service in tourism destination. The last three dimensions of perceived risks identify, moreover, that consumers with high-perceived safety risk do not pursue the offline service or sharing platform because of lack of identity information. Both drivers and passengers expect a certain level of safety when using Grab cars service due to a particular number of assaults incident happened in the past between both sides. Grab; meanwhile; facilitates efficient and essential information to leverage safety level for both sides. Not only Grab drivers but passengers receive full identical information of whom they are trading with. Online Platform Company, additional compiled a safety checklist following training sessions for drivers to confront with any worst-case scenarios that may arise while they are out on the road. On the other hand, performance risk and social risk were presented from this study as the elements not effecting on passengers' satisfaction and intention to use Grab service amid Covid-19 crisis. Previously, people would express their anxiety whether their satisfaction is met in the trip with Grab. Passengers also intend choose the most suitable online taxi providers to meet their social status. The result, nevertheless, showed that they intend to worry more about their safety at most since Corona Virus is spreading out. As a result, performance risk and social risk are not the skeletal factors in the relationship between perceived risks and consumer satisfaction and intention to use Grab service amid Covid-19 crisis.

\section{Conclusions}

In this study, the relationship between customer satisfaction and intentions to use Grab service amid Covid-19 crisis and four perceived risks were centered and discussed. The results from this study play important theoretical and practical implications. Initially, this study proves a presented relationship between four perceived risks including psychological risk, social risk, safety risk and performance risk and consumer satisfaction and intentions to use Grab service. Furthermore, only some dimensions of perceived risks were identified to significantly negatively effect on customer satisfaction and intentions to use Grab service during Covid-19 crisis. As a result, other researchers could easily under the most vital areas of perceived risk among this unsettling time. Additionally, by finding a totally different view of approaching perceived risk in a time compared to the antecedent research, this research adds more support to this field.

\subsection{Managerial Implications}

This study has contributed vitally to practical implications of perceived risk theory in Vietnam situation. Firstly, safety risk and psychological risk have significant effects on consumer satisfaction and intention 
to use Grab service. Initially, people intend to choose Grab service over traditional taxis by receiving transparency identical information when using Grab service, from forecasted price, pick-up location, arrival time, license plate and driver rating. Moreover, not only passengers but drivers were concerned about their own safety and information security. Online platform taxi drivers are well-trained and equipped from their company to deal with any incidents that may happen during their working time on the road. Therefore, consumers will find more satisfied when choosing Grab service. The influence of psychological risk and safety risk on consumer satisfaction and intentions to use Grab service is presented more obviously during Covid-19 crisis. At this moment, taxi usage demands could decrease or collapse tragically if consumers do not see the safety that Grab service provide to them. Furthermore, people are banned from travelling but essential needs, which also come from protecting purpose to prevent people from getting infectious deceases. Consequently, performance risk and social risk are no longer the primary factors to drive or satisfy Vietnamese consumers to use Grab service. As a result, platform safety and psychological risk play a vital part for customers' intention to use Grab service during the pandemic. Hence, it is important for managers to concentrate on building a good image of the safety platform to win the hearts and minds of their customers amid pandemics.

\subsection{Research limitations}

It was impossible to avoid limitation in this research. First, due to lockdown period, in the data collection method, questionnaires were distributed to respondents and it unexpectedly excludes all the respondents who cannot read or do not have enough knowledge to understand the survey questions. Second, restriction comes from the demographic characteristics of sample. Most of respondents are student and has low to middle income each month. Therefore, the research results should be applied and generalized for this target customer. Even though the recommended research model has found out the relationship between these variables, it is still needed to conduct a research to find out more variables which can predict better and more accuracy customer intention. Third, this study just used survey as a single way to collect data. Because of the limitations which were discussed above, the author also suggested some direction for future research. Further investigation should be conducted to find out the impact of personality and demographics on customers intention. As the development and popular of online shopping, future research should replicate similar study to investigate factors impact customer actual behavior rather than just their intention. Finally, the research in the future can avoid limitation from data collection method by using more than one way to collect data such as: longitudinal studies, focus groups and interview.

\section{Acknowledgement}

The authors would like to thank the anonymous referees for constructive comments on earlier version of this paper.

\section{References}

Bagozzi, R. P., \& Foxall, G. R. (1996). Construct validation of a measure of adaptive-innovative cognitive styles in consumption. International Journal of Research in Marketing, 13(3), 201-213.

Bartel, E., MacEachen, E., Reid-Musson, E., Meyer, S. B., Saunders, R., Bigelow, P., ... \& Varatharajan, S. (2019). Stressful by design: Exploring health risks of ride-share work. Journal of Transport \& Health, 14, 100571.

Botsman, R., \& Rogers, R. (2010). Beyond Zipcar: Collaborative consumption. Harvard Business Review, 88(10), 30 .

Chang, W. L., \& Wang, J. Y. (2018). Mine is yours? Using sentiment analysis to explore the degree of risk in the sharing economy. Electronic Commerce Research and Applications, 28, 141-158.

Choi, H. J., \& Park, J. (2014). Study on the local factors affecting availability of car-sharing in seoul. Journal of the Korean Society for Railway, 17(5), 381-389. 
Fornell, C., Larcker, D. F. (1981). Evaluating structural equation models with unobservable variables and measurement error. Journal of Marketing Research, 18(1), 39-50

Joo, J. H. (2017). Motives for participating in sharing economy: Intentions to use car sharing services. The Journal of Distribution Science, 15(2), 21-26.

Jacoby, J., \& Kaplan, L.B. (1972). The Components of Perceived Risk, in Proceedings, Third annual Conference of the Association for Consumer Research, M. Venkatesan, ed. College Park, MD: Association for Consumer Research

Gao, Y., \& Chen, J. (2019). The risk reduction and sustainable development of shared transportation: The Chinese online car-hailing policy evaluation in the digitalization era. Sustainability, 11(9), 2596.

Gaski, J.F., \& Nevin, J. R. (1985). The differential effects of exercised and unexercised power sources in a marketing channel. Journal of Marketing Research, 22(5), 130-142.

Hawapi, M. W., Sulaiman, Z., Kohar, U. H. A., \& Talib, N. A. (2017). Effects of perceived risks, reputation and electronic word of mouth (e-WOM) on collaborative consumption of uber car sharing service. In IOP Conference Series: Materials Science and Engineering (Vol. 215, No. 1, p. 012019).

Hair, J. F., Anderson, R. E., Tatham, R. L., \& Black, W. C. (1998). Multivariate Data Analysis, $5^{\text {th }}$ ed. London: Prentice-Hall International.

Khedmatgozar, H. R., \& Shahnazi, A. (2017). The role of dimensions of perceived risk in adoption of corporate Internet banking by customers in Iran. Electronic Commerce Research, 18(2), 389-412

Kim, S., Lee, K., \& Choi, K. (2014). Preferences factors analysis for car-sharing. Journal of the Korean Society of Civil Engineers, 34(4), 1241-1249.

Lee, Z. W. Y., Chan, T.K.H., Balaji, M. S., \& Chong, A.Y.L. (2018). Why people participate in the sharing economy: An empirical investigation of Uber. Internet Research, 28(3), 829-850.

Lessig, L. (2008). Remix: Making art and commerce thrive in the hybrid economy. New York: Penguin Press.

Liang, X.B., Li, J.J., \& Xu, Z. (2018). The impact of perceived risk on customers' intention to use: An empirical analysis of DiDi car-sharing services. In Proceedings of The $18 t$ International Conference on Electronic Business, 644-653.

Malazizi, N., Alipour, H., \& Olya, H. (2018). Risk perceptions of Airbnb Hosts: Evidence from a Mediterranean island. Sustainability, 10(5), 1-23.

Mohamad,W. A., Fuad, A. M., Shahib, N.S. , Azm, A., Kamal, S. M., \& Abdullah, D. (2016). Framework of customer's intention to use uber service in tourism destination. International Academic Research Journal of Business and Technology, 2(2), 102-106.

Park, S., \& Tussyadiah, I. P. (2017). Multidimensional facets of perceived risk in mobile travel booking. Journal of Travel Research, 56(7), 854-867.

Pavlou, P.A., \& Gefen, D. (2004). Building effective online marketplaces with institution-based trust. Information Systems Research, 15(1), 37-59.

Wan, W. N. A. A. B., Mohamad, A. F. M. F., Shahib, N. S., Azmi, A., Kamal, S. B. M., \& Abdullah, D. A. (2016). Framework of customer's intention to use Uber service in tourism destination. International Academic Research Journal of Business and Technology, 2(2), 102-106.

Sakunlertvattana, W. (2016). Factors Influencing Consumer Brand Choice of Top 3 Taxi Booking Mobile Applications in Bangkok: Uber, GrabTaxi and Easy Taxi.

Shaheen, S. A., Chan, N. D., \& Gaynor, T. (2016). Casual carpooling in the San Francisco Bay Area: Understanding user characteristics, behaviors, and motivations. Transport Policy, 51, 165-173.

Schaefers, T., Lawson, S. J., \& Kukar-Kinney, M. (2016). How the burdens of ownership promote consumer usage of access-based services. Marketing Letters, 27(3), 569-577.

Zhang, L., Tan, W., Xu, Y., \& Tan, G. (2012). Dimensions of consumers' perceived risk and their influences on online consumers' purchasing behavior. Communications in Information Science and Management Engineering, 2(7), 8-14. 
C 2020 by the authors; licensee Growing Science, Canada. This is an open access article distributed under the terms and conditions of the Creative Commons Attribution (CCBY) license (http://creativecommons.org/licenses/by/4.0/). 